\title{
Article
}

\section{The Neuroprotective Effect of Thiopental on the Postoperative Neurological Complications in Patients Undergoing Surgical Clipping of Unruptured Intracranial Aneurysm: A Retrospective Analysis}

\author{
Byung-Gun Kim ${ }^{1,+}$, Young-Tae Jeon ${ }^{2,3,+}$, Jiwon Han ${ }^{3}$, Yu Kyung Bae ${ }^{3}$, Si Un Lee ${ }^{4}$, Jung-Hee Ryu ${ }^{2,3}$ \\ and Chang-Hoon $\mathrm{Koo}^{3, *(\mathbb{D})}$ \\ 1 Department of Anesthesiology and Pain Medicine, Inha University School of Medicine, \\ Inha University Hospital, Incheon 22332, Korea; wangunlone@gmail.com \\ 2 Department of Anesthesiology and Pain Medicine, Seoul National University College of Medicine, \\ Seoul 03080, Korea; ytjeon@snubh.org (Y.-T.J.); jinaryu74@gmail.com (J.-H.R.) \\ 3 Department of Anesthesiology and Pain Medicine, Seoul National University Bundang Hospital, \\ Seongnam 13620, Korea; hanjiwon@snubh.org (J.H.); vansuri27@gmail.com (Y.K.B.) \\ 4 Department of Neurosurgery, Seoul National University Bundang Hospital, Seongnam 13620, Korea; \\ bigmidget@hanmail.net \\ * Correspondence: vollock9@gmail.com; Tel.: +82-31-787-7497; Fax: +82-31-787-4063 \\ + These two authors equally contributed to this work as co-first authors.
}

Citation: Kim, B.-G.; Jeon, Y.-T.; Han, J.; Bae, Y.K.; Lee, S.U.; Ryu, J.-H.; Koo, C.-H. The Neuroprotective Effect of Thiopental on the Postoperative Neurological Complications in Patients Undergoing Surgical Clipping of Unruptured Intracranial Aneurysm: A Retrospective Analysis. J. Clin. Med. 2021, 10, 1197. https://doi.org/ $10.3390 /$ jcm 10061197

Received: 10 February 2021

Accepted: 11 March 2021

Published: 12 March 2021

Publisher's Note: MDPI stays neutral with regard to jurisdictional claims in published maps and institutional affiliations.

Copyright: (c) 2021 by the authors. Licensee MDPI, Basel, Switzerland. This article is an open access article distributed under the terms and conditions of the Creative Commons Attribution (CC BY) license (https:// creativecommons.org/licenses/by/ $4.0 /)$.

\begin{abstract}
Although thiopental improved neurological outcomes in several animal studies, there are still insufficient clinical data examining the efficacy of thiopental for patients undergoing surgical clipping of unruptured intracranial aneurysm (UIA). This study validated the effect of thiopental and investigated risk factors associated with postoperative neurological complications in patients undergoing surgical clipping of UIA. In total, 491 patients who underwent aneurysm clipping were included in this retrospective cohort study. Data regarding demographics, aneurysm characteristics, and use of thiopental were collected from electronic medical records. Propensity score matching and logistic regression analysis were used. After propensity score matching, the thiopental group showed a lower incidence of the postoperative neurological complications than non-thiopental group (5.5\% vs. $17.1 \%, p=0.001)$. In multivariate analysis, thiopental reduced the risk of postoperative neurological complications (odds ratio (OR) $0.26,95 \%$ confidence interval (CI) 0.13 to $0.51, p<0.001$ ) while aneurysm size $\geq 10 \mathrm{~mm}$ (OR $4.48,95 \%$ CI 1.69 to $11.87, p=0.003$ ), and hyperlipidemia (OR 2.24, $95 \%$ CI 1.16 to $4.32, p=0.02$ ) increased the risk of postoperative neurological complications. This study showed that thiopental was associated with the lower risk of neurological complications after clipping of UIA.
\end{abstract}

Keywords: intracranial aneurysm; neurosurgery; postoperative complications; thiopental

\section{Introduction}

Unruptured intracranial aneurysm (UIA) has a reported incidence of up to $3 \%$ in the general population [1]. Surgical clipping is considered suitable for the treatment of UIA. During surgical clipping of UIA, temporary clipping of parent artery is commonly performed to soften the UIA, thereby reducing intraoperative rupture and facilitating approach to vessels $[2,3]$. However, temporary clipping is associated with cerebral ischemia and postoperative neurological complications [4-6]. Cerebral infarction occurs in approximately $11 \%$ of patients who have undergone surgical clipping of UIA [7]. Some measures, such as hypothermia, neurophysiologic monitoring, or pharmacological interventions, have been suggested to prevent neurological impairment after UIA clipping [8-10].

Thiopental, as a pharmacological treatment, has been known to have neuroprotective effect of brain over the years [11,12]. Thiopental induces burst suppression, which 
decreases cerebral metabolism and redistributes cerebral blood flow [13]. However, this neuroprotective effect of thiopental was addressed only in animal models [11]. There has been little discussion on the neuroprotective effect of thiopental in humans.

Since postoperative neurological complications are associated with mortality, morbidity, and prolonged length of hospital stay, several studies have established risk factors for postoperative neurological complications in patients undergoing surgical clipping of UIA $[14,15]$. However, those studies rarely considered the effect of thiopental on the postoperative neurological complications. Therefore, this study was performed to establish the clinical efficacy of thiopental during surgical clipping of UIA and to investigate the risk factors associated with postoperative neurological complications after clipping of UIA.

\section{Materials and Methods}

\subsection{Study Design}

This study was approved by the Institutional Review Board (IRB) of Seoul National University Bundang Hospital, Seongnam, Korea (IRB approval number: B-1710/427-113). The requirement for informed consent was waived due to the retrospective nature of the study design. Patients who had been diagnosed with UIA and had undergone surgical clipping at our institution between May 2003 and August 2016 were included in this study. The exclusion criteria were as follows: (1) Concomitant brain tumor that would affect postoperative neurological complications, and (2) UIA associated with arteriovenous malformation or arteriovenous fistula.

\subsection{Data Collection}

The following data were collected from electronic medical records: Sex, age, height, weight, smoking history, alcohol use, concomitant diseases, size of aneurysm, number of aneurysms, locations of aneurysms, anesthesia time, operation time, intraoperative hemodynamics, intravenous thiopental administration, and laboratory data. Aneurysm size was defined as the larger of width or height according to the previous study [16]. Aneurysms were categorized according to size (i.e., $<5 \mathrm{~mm}, 5-10$, or $\geq 10 \mathrm{~mm}$ ), number (i.e., 1 or $>1$ ), and location (i.e., middle cerebral artery, internal carotid artery, anterior communicating artery, other anterior circulation, posterior circulation, or $>2$ sites). A neurosurgeon who was not involved in the surgeries determined the presence of postoperative neurological complications, including transient ischemic attack or acute infarction.

\subsection{Surgery and Anesthesia}

Experienced neurosurgeons performed surgical clipping, using standard craniotomy procedures, in patients who had UIA with bleb, those who had uncoilable UIA due to location or shape, or those who refused to receive endovascular coiling. Temporary clips were routinely placed to soften the aneurysm and to reduce intraoperative rupture. A bolus of $200 \mathrm{mg}$ of thiopental was administered immediately before application of the temporary clip at the attending surgeon's discretion. Anesthesia was induced and maintained by total intravenous anesthesia using propofol and remifentanil.

\subsection{Statistical Analysis}

Demographic variables are expressed as means \pm standard deviations (continuous variables) or number with percentage (categorical variables). To minimize the effect of confounding variables, propensity score (PS) matching was performed using the nearest neighbor method at a 1:1 ratio, without replacement and a caliper of 0.2 . PS was calculated by logistic regression analysis including all preoperative variables, intraoperative variables, and characteristics of UIA. Univariate logistic regression analysis was performed to identify risk factors for postoperative neurological complications. Subsequently, variables with $p<0.2$ in univariate analysis were included in multivariate analysis using forward selection. In all analyses, $p<0.05$ was considered to indicate statistical significance. Statistical analyses were performed using SPSS Statistics, version 24 (IBM Corp., Armonk, NY, USA). 


\section{Results}

In total, 491 patients who had undergone surgical clipping of UIA were enrolled in this study. Fifty-one out of 491 patients (10.4\%) experienced neurological complications after clipping surgery of UIA. Among the total of 491 patients, 263 patients were administered thiopental (TPT group) during surgical clipping while 228 patients did not receive thiopental during surgery (Non-TPT group). After PS matching, 181 patients were allocated to each group. Table 1 represents the results of comparative analysis of the two groups between and after PS matching. After matching, standardized mean difference, less than 0.2 , indicated well balance and significant differences between two groups were not observed in all variables $(p>0.05)$.

Table 1. Comparisons of demographic variables before and after propensity score matching.

\begin{tabular}{|c|c|c|c|c|c|c|}
\hline \multirow[t]{2}{*}{ Variables } & \multicolumn{3}{|c|}{ Entire Cohort $(n=491)$} & \multicolumn{3}{|c|}{ PS-Matched Cohort $(n=362)$} \\
\hline & $\begin{array}{c}\text { TPT } \\
n=263\end{array}$ & $\begin{array}{c}\text { Non-TPT } \\
n=228\end{array}$ & SMD & $\begin{array}{c}\text { TPT } \\
n=181\end{array}$ & $\begin{array}{c}\text { Non-TPT } \\
n=181\end{array}$ & SMD \\
\hline \multicolumn{7}{|l|}{ Preoperative variables } \\
\hline Sex: Female & $185(70.3 \%)$ & $148(64.9 \%)$ & 0.116 & $132(72.9 \%)$ & $118(65.2 \%)$ & 0.168 \\
\hline Age (Year) & $59.9 \pm 10.4$ & $59.0 \pm 9.9$ & 0.091 & $59.4 \pm 9.7$ & $59.2 \pm 9.8$ & 0.023 \\
\hline Height $(\mathrm{cm})$ & $159.2 \pm 9.7$ & $159.5 \pm 8.5$ & 0.032 & $158.6 \pm 10.3$ & $159.3 \pm 8.4$ & 0.067 \\
\hline Weight (kg) & $61.8 \pm 10.6$ & $62.4 \pm 10.7$ & 0.056 & $61.7 \pm 10.5$ & $62.0 \pm 11.0$ & 0.031 \\
\hline Smoker & $31(11.8 \%)$ & $43(18.9 \%)$ & 0.197 & $28(15.5 \%)$ & $30(16.6 \%)$ & 0.030 \\
\hline Alcohol & $30(11.4 \%)$ & $40(17.5 \%)$ & 0.175 & $25(13.8 \%)$ & $31(17.1 \%)$ & 0.092 \\
\hline Hypertension & $139(52.9 \%)$ & $126(55.3 \%)$ & 0.048 & $102(56.4 \%)$ & $101(55.8 \%)$ & 0.011 \\
\hline Diabetes Mellitus & $28(10.6 \%)$ & $24(10.5 \%)$ & 0.004 & $20(11.0 \%)$ & $20(11.0 \%)$ & $<0.001$ \\
\hline Coronary Heart Disease & $8(3.0 \%)$ & $12(5.3 \%)$ & 0.112 & $7(3.9 \%)$ & $8(4.4 \%)$ & 0.028 \\
\hline Thyroid disease & $8(3.0 \%)$ & $16(7.0 \%)$ & 0.183 & $8(4.4 \%)$ & $10(5.5 \%)$ & 0.051 \\
\hline Hyperlipidemia & $46(17.5 \%)$ & $48(21.1 \%)$ & 0.090 & $37(20.4 \%)$ & $36(19.9 \%)$ & 0.014 \\
\hline \multicolumn{7}{|l|}{ Characteristics of UIA } \\
\hline Aneurysm size (mm) & & & 0.176 & & & 0.047 \\
\hline$<5$ & $146(55.5 \%)$ & $143(62.7 \%)$ & & $108(59.7 \%)$ & $112(61.9 \%)$ & \\
\hline $5 \leq<10$ & $105(39.9 \%)$ & $72(31.6 \%)$ & & $65(35.9 \%)$ & $61(33.7 \%)$ & \\
\hline$\geq 10$ & $12(4.6 \%)$ & $13(5.7 \%)$ & & $8(4.4 \%)$ & $8(4.4 \%)$ & \\
\hline Multiplicity & & & 0.315 & & & 0.041 \\
\hline 1 & $186(70.7 \%)$ & $191(83.8 \%)$ & & $143(79.0 \%)$ & $146(80.7 \%)$ & \\
\hline$>1$ & $77(29.3 \%)$ & $37(16.2 \%)$ & & $38(21.0 \%)$ & $35(19.3 \%)$ & \\
\hline Location & & & 0.563 & & & 0.179 \\
\hline MCA & $181(68.8 \%)$ & $108(47.4 \%)$ & & $108(59.7 \%)$ & $99(54.7 \%)$ & \\
\hline ICA & $5(1.9 \%)$ & $4(1.8 \%)$ & & $4(2.2 \%)$ & $4(2.2 \%)$ & \\
\hline Acom & $20(7.6 \%)$ & $37(16.2 \%)$ & & $20(11.0 \%)$ & $26(14.4 \%)$ & \\
\hline Other anterior circulation & $25(9.5 \%)$ & $51(22.4 \%)$ & & $23(12.7 \%)$ & $31(17.1 \%)$ & \\
\hline Posterior circulation & $0(0.0 \%)$ & $5(2.2 \%)$ & & $26(14.4 \%)$ & $21(11.6 \%)$ & \\
\hline More than 2 sites & $32(12.2 \%)$ & $23(10.1 \%)$ & & $108(59.7 \%)$ & $99(54.7 \%)$ & \\
\hline \multicolumn{7}{|l|}{ Intraoperative variables } \\
\hline Anesthesia time (min) & $330.3 \pm 83.7$ & $294.3 \pm 76.3$ & 0.449 & $302.2 \pm 52.1$ & $302.1 \pm 79.4$ & 0.001 \\
\hline Operation time (min) & $265.6 \pm 80.3$ & $230.3 \pm 72.7$ & 0.461 & $238.7 \pm 49.4$ & $237.9 \pm 75.7$ & 0.012 \\
\hline Highest SBP (mmHg) & $147.7 \pm 16.4$ & $145.9 \pm 22.7$ & 0.092 & $147.9 \pm 17.8$ & $146.8 \pm 23.2$ & 0.054 \\
\hline Lowest SBP (mmHg) & $87.5 \pm 9.7$ & $86.1 \pm 9.1$ & 0.155 & $86.2 \pm 9.7$ & $86.2 \pm 9.1$ & 0.001 \\
\hline $\begin{array}{l}\text { Estimated blood loss }(\mathrm{mL}) \\
\text { Laboratory variables }\end{array}$ & $577.6 \pm 460.2$ & $469.5 \pm 334.2$ & 0.269 & $471.3 \pm 252.1$ & $475.6 \pm 318.8$ & 0.015 \\
\hline Preoperative $\mathrm{Hb}$ (g/dL) & $13.6 \pm 1.4$ & $13.7 \pm 1.4$ & 0.035 & $13.6 \pm 1.3$ & $13.7 \pm 1.3$ & 0.041 \\
\hline Postoperative $\mathrm{Hb}(\mathrm{g} / \mathrm{dL})$ & $11.4 \pm 1.5$ & $11.5 \pm 1.3$ & 0.066 & $11.4 \pm 1.5$ & $11.4 \pm 1.3$ & 0.006 \\
\hline $\begin{array}{l}\text { Preoperative WBC } \\
\qquad\left(10^{3} / \mu \mathrm{L}\right)\end{array}$ & $6.7 \pm 2.5$ & $6.4 \pm 1.9$ & 0.131 & $6.7 \pm 2.3$ & $6.5 \pm 2.0$ & 0.131 \\
\hline $\begin{array}{c}\text { Postoperative WBC } \\
\left(10^{3} / \mu \mathrm{L}\right)\end{array}$ & $8.7 \pm 3.8$ & $7.7 \pm 3.2$ & 0.287 & $8.3 \pm 3.6$ & $7.7 \pm 3.1$ & 0.150 \\
\hline
\end{tabular}

Abbreviations: SMD, standardized mean difference; UIA, unruptured intracranial aneurysm; MCA, middle cerebral artery; ICA, internal carotid artery; Acom, anterior communicating artery; SBP, systolic blood pressure; Hb, hemoglobin; WBC, white blood cell. Data are expressed as mean \pm SD or number $(\%)$. 
As shown in Table 2, postoperative neurological complications were significantly lower in the TPT group than the non-TPT group. The significant difference was found not only in the entire cohort analysis (odds ratio (OR) $0.26,95 \%$ confidence interval (CI) 0.13 to $0.50, p<0.001$ ), but also in the PS-matched cohort analysis (OR $0.28,95 \%$ CI 0.13 to 0.60 , $p=0.001)$.

Table 2. Postoperative neurological complications after surgical clipping of UIA before and after propensity score matching.

\begin{tabular}{cccc}
\hline Variables & Event Rate & OR (95\% CI) & $p$ Value \\
\hline Entire cohort (before PSM) & 38 of $228(16.7 \%)$ & 1 & $<0.001$ \\
Non-TPT group & 13 of $263(4.9 \%)$ & $0.26(0.13$ to 0.50$)$ & 0.001 \\
TPT group & & 1 & \\
PS-matched cohort (After PSM) & 31 of $181(17.7 \%)$ & $0.28(0.13$ to 0.60$)$ & \\
Non-TPT group & 10 of $181(5.5 \%)$ & \\
TPT group & P
\end{tabular}

Abbreviations: PSM, propensity score matching; OR, odds ratio; TPT, thiopental.

The results of univariate and multivariate logistic regression analysis are shown in Tables 3 and 4 . The result of multivariate analysis showed that intraoperative thiopental administration significantly reduced the postoperative neurological complications (OR 0.26 , $95 \%$ CI 0.13 to $0.51, p<0.001)$. The multivariate model revealed the risk factors of postoperative neurological complications in patients that underwent surgical clipping of UIA aneurysm size $\geq 10 \mathrm{~mm}$ (OR 4.48, 95\% CI 1.69 to $11.87, p=0.003$ ) and hyperlipidemia (OR 2.24, 95\% CI 1.16 to $4.32, p=0.02$ ). The multivariate model showed an adequate goodness-of-fit, assessed by Hosmer and Lemeshow test $(p=0.43)$.

Table 3. Univariate logistic regression analysis of risk factors for postoperative neurological complications.

\begin{tabular}{|c|c|c|}
\hline Variables & Odds Ratio (95\% CI) & $p$ Value \\
\hline \multicolumn{3}{|l|}{ Demographic data } \\
\hline Sex & $0.96(0.51$ to 1.79$)$ & 0.90 \\
\hline Age & $1.02(0.99$ to 1.05$)$ & 0.25 \\
\hline Height & $1.00(0.97$ to 1.03$)$ & 0.98 \\
\hline Weight & 1.01 (0.98 to 1.04$)$ & 0.57 \\
\hline Hypertension & $1.25(0.69$ to 2.24$)$ & 0.46 \\
\hline Diabetes Mellitus & $1.98(0.90$ to 4.34$)$ & 0.09 \\
\hline Coronary heart disease & $0.96(0.22$ to 4.25$)$ & 0.95 \\
\hline Thyroid disease & $1.25(0.36$ to 4.34$)$ & 0.73 \\
\hline Hyperlipidemia & $2.36(1.25$ to 4.44$)$ & $0.008 *$ \\
\hline \multicolumn{3}{|l|}{ Characteristics of Aneurysm } \\
\hline \multicolumn{3}{|l|}{ Size } \\
\hline$<5$ & 1 & \\
\hline $5 \leq<10$ & $0.86(0.45$ to 1.66$)$ & 0.65 \\
\hline$\geq 10$ & $4.39(1.74$ to 11.08$)$ & $0.002 *$ \\
\hline \multicolumn{3}{|l|}{ Multiplicity } \\
\hline 1 & 1 & \\
\hline$>1$ & 1.14 (0.58 to 2.22$)$ & 0.71 \\
\hline \multicolumn{3}{|l|}{ Location } \\
\hline MCA & 1 & \\
\hline Acom & 0.97 (0.36 to 2.65$)$ & 0.96 \\
\hline Other anterior circulation & $1.87(0.90$ to 3.90$)$ & 0.10 \\
\hline ICA/Posterior circulation & - & - \\
\hline More than 2 sites & $1.72(0.74$ to 4.03$)$ & 0.21 \\
\hline \multicolumn{3}{|l|}{ Intraoperative variables } \\
\hline Anesthesia time (min) & 1.00 & - \\
\hline Operation time (min) & 1.00 & - \\
\hline
\end{tabular}


Table 3. Cont.

\begin{tabular}{ccc}
\hline Variables & Odds Ratio (95\% CI) & $p$ Value \\
\hline Highest SBP $(\mathrm{mmHg})$ & $1.00(0.99$ to 1.02$)$ & 0.78 \\
Lowest SBP $(\mathrm{mmHg})$ & $1.00(0.97$ to 1.03$)$ & $<.88$ \\
Use of thiopental & $0.26(0.14$ to 0.50$)$ & - \\
Estimated blood loss $(\mathrm{mL})$ & 1.00 & 0.70 \\
Laboratory variables & & 0.52 \\
Preoperative Hb $(\mathrm{g} / \mathrm{dL})$ & $0.96(0.78$ to 1.18$)$ & 0.09 \\
Postoperative Hb $(\mathrm{g} / \mathrm{dL})$ & $1.07(0.87$ to 1.32$)$ & 0.43 \\
Preoperative WBC $\left(10^{3} / \mu \mathrm{L}\right)$ & $0.87(0.74$ to 1.02$)$ & \\
Postoperative WBC $\left(10^{3} / \mu \mathrm{L}\right)$ & $0.97(0.89$ to 1.05$)$ & \\
\hline
\end{tabular}

$\mathrm{CI}$, confidence intervals; MCA, middle cerebral artery; Acom, anterior communicating artery; ICA, internal carotid artery; SBP, systolic blood pressure. ${ }^{*} p<0.05$.

Table 4. Multivariate logistic regression analysis of risk factors for postoperative neurological complications.

\begin{tabular}{ccc}
\hline Variables & Odds Ratio (95\% CI) & $p$ Value \\
\hline Use of thiopental & $0.26(0.13$ to 0.51$)$ & $<0.001$ \\
Size of aneurysm $\geq 10 \mathrm{~mm}$ & $4.48(1.69$ to 11.87$)$ & 0.003 \\
Hyperlipidemia & $2.24(1.16$ to 4.32$)$ & 0.02 \\
\hline
\end{tabular}

CI, Confidence intervals; RBC, Red blood cell.

\section{Discussion}

This retrospective analysis showed that intraoperative thiopental administration significantly reduced the postoperative neurological complications in patients undergoing surgical clipping of UIA. This neuroprotective effect of thiopental was also observed in the multivariate model of entire cohort. This study also showed that aneurysm size and hyperlipidemia were independently associated with postoperative neurological complications in patients who underwent UIA clipping.

This study proved the neuroprotective effect of thiopental in patients undergoing surgical clipping of UIA. Thiopental administration has been described as an effective method to prevent postoperative neurological deficits in several animal studies [17-21]. There are several proposed mechanisms for cerebral protection of thiopental. First, thiopental improves cerebral oxygenation. Thiopental modulates NMDA receptors, depressing the inward current [22]. Subsequently, it reduces the cerebral metabolic rate of oxygen, thereby decreasing oxygen consumption in ischemic area [21]. Second, thiopental causes "inverse steal" phenomenon, a redistribution of cerebral blood flow from hyper-perfused region to hypo-perfused region [23]. Third, thiopental have an anti-oxidative effect through inhibiting hydroxyl radical generation and lipid peroxidation [24]. However, the clinical efficacy of thiopental for human still remains unclear. Several studies have shown that the duration of burst suppression is insufficient to protect against cerebral ischemia [25,26]. In these previous studies, inhalation anesthetics were used to maintain anesthesia. Interestingly, the most remarkable point of the present study is that intravenous anesthetics were administered throughout the operation. Total intravenous anesthesia has been reported to provide a longer duration and higher degree of burst suppression, compared to inhalational anesthetics [27]. This factor appears to be responsible for favorable effect of thiopental in the present study. To the best of our knowledge, this study is the first study to support neuroprotective effect of thiopental in patients who had UIA clipping surgery under total intravenous anesthesia.

Aneurysm size $\geq 10 \mathrm{~mm}$ was significantly associated with poor neurological outcome in the present study. In previous studies, large aneurysm size was associated with surgery-related mortality and morbidity $[28,29]$. Similar to our findings, large aneurysm size has been shown to predict postoperative neurological complications in patients undergoing not only surgical clipping [28-30], but also endovascular coiling for UIA [31]. Aneurysm size $\geq 10 \mathrm{~mm}$ was associated with an approximately three-fold increase in 
the rate of postoperative neurological complications. These findings suggest that large aneurysms may increase thromboembolic risk, thereby causing neurological deficits [32]. Another possible explanation is that large aneurysms may provide intracranial mass and unexpected tissue transformation [33]. Large UIA is challenging for neurosurgeons due to thick and atheromatous wall, intramural thrombus, calcification, and incorporated perforating arteries [2]. Temporary clipping facilitates surgical procedures, that is, safe dissection of UIA and preservation of other vessels [34]. During the temporary clipping, thiopental administration promotes collateral circulation and reduces the risk of postoperative neurological complications [34]. A previous report insisted that temporary clipping with barbiturate administration may be a safe technique for large UIA [34].

As reported by previous studies $[35,36]$, hyperlipidemia was an independent risk factor for postoperative neurological complications. This may be attributed to vascular fragility and atherosclerosis, inducing reduction in cerebral blood flow and cerebral perfusion [36-38].

Although previous studies found that age is an important risk factor associated with surgical outcomes, the current study does not support previous result in this area. The risk for surgery substantially increases for patients about 50 years and older [7]. Therefore, it is recommended to consider the patient's age on the decision of treatment. Contrarily, age seems to be insignificant factor for postoperative neurological complications in this study. This discordant result may be explained by a great proportion of old patients $(\geq 50)$ in this study. A total of $83.1 \%$ of included patients were $\geq 50$, thus more patients who are $<50$ may be needed to show the effect of age on postoperative neurological complications in this study. On the other hand, apart from this disagreement, our finding appears to be well substantiated by several studies reporting insignificant association between age and surgical outcomes $[28,39,40]$.

This study had some limitations. First, neurological complications were evaluated only during the hospital stay; therefore, further studies with long-term follow-up are needed to confirm the findings. Second, temporary clip may be a risk factor for postoperative neurological complications, thus data such as duration and number of temporary clips had been tried to be collected. However, it was impossible to reveal the effect of temporary clip because information had not been recorded in detail. Further studies regarding temporary clip may be needed.

\section{Conclusions}

In conclusion, this retrospective study showed that intraoperative thiopental administration was associated with a reduction in the postoperative neurological complications in patients undergoing surgical clipping of UIA. The finding of the present study provides a considerable clinical implication that use of thiopental may be a reasonable strategy to prevent cerebral ischemia or infarction during UIA surgery. Further prospective randomized trials are encouraged to validate the results of the present study.

Author Contributions: Conceptualization, B.-G.K. and Y.-T.J.; methodology, B.-G.K., Y.-T.J., S.U.L., and C.-H.K.; software, C.-H.K.; validation, J.H., Y.K.B., and J.-H.R.; formal analysis, S.U.L. and J.-H.R.; investigation, J.H. and Y.K.B.; data curation, C.-H.K.; writing-original draft preparation, B.-G.K. and C.-H.K.; writing-review and editing, Y.-T.J. and C.-H.K.; supervision, C.-H.K. All authors have read and agreed to the published version of the manuscript.

Funding: This research received no external funding.

Institutional Review Board Statement: The study was conducted according to the guidelines of the Declaration of Helsinki, and approved by the Institutional Review Board of Seoul National University Bundang Hospital (protocol number: B-1710/427-113; date of approval: 10 October 2017).

Informed Consent Statement: Patient consent was waived due to the retrospective nature of this study. 
Data Availability Statement: The datasets generated and analyzed during the current study are available on request to the corresponding author on reasonable request.

Conflicts of Interest: The authors declare no conflict of interest.

\section{References}

1. Williams, L.N.; Brown, R.D., Jr. Management of unruptured intracranial aneurysms. Neurol. Clin. Pract. 2013, 3, 99-108. [CrossRef] [PubMed]

2. Batjer, H.H.; Frankfurt, A.I.; Purdy, P.D.; Smith, S.S.; Samson, D.S. Use of etomidate, temporary arterial occlusion, and intraoperative angiography in surgical treatment of large and giant cerebral aneurysms. J. Neurosurg. 1988, 68, 234-240. [CrossRef]

3. Dhandapani, S.; Pal, S.S.; Gupta, S.K.; Mohindra, S.; Chhabra, R.; Malhotra, S.K. Does the impact of elective temporary clipping on intraoperative rupture really influence neurological outcome after surgery for ruptured anterior circulation aneurysms?A prospective multivariate study. Acta Neurochir. 2013, 155, 237-246. [CrossRef]

4. Samson, D.; Batjer, H.H.; Bowman, G.; Mootz, L.; Krippner, W.J., Jr.; Meyer, Y.J.; Allen, B.C. A clinical study of the parameters and effects of temporary arterial occlusion in the management of intracranial aneurysms. Neurosurgery 1994, 34, $22-28$.

5. Taylor, C.L.; Selman, W.R.; Kiefer, S.P.; Ratcheson, R.A. Temporary vessel occlusion during intracranial aneurysm repair. Neurosurgery 1996, 39, 893-905. [PubMed]

6. Lavine, S.D.; Masri, L.S.; Levy, M.L.; Giannotta, S.L. Temporary occlusion of the middle cerebral artery in intracranial aneurysm surgery: Time limitation and advantage of brain protection. Neurosurg. Focus 1997, 2, e4. [CrossRef]

7. Wiebers, D.O.; Whisnant, J.P.; Huston, J., III; Meissner, I.; Brown, R.D., Jr.; Piepgras, D.G.; Forbes, G.S.; Thielen, K.; Nichols, D.; O'Fallon, W.M.; et al. Unruptured intracranial aneurysms: Natural history, clinical outcome, and risks of surgical and endovascular treatment. Lancet 2003, 362, 103-110. [CrossRef]

8. Minamisawa, H.; Nordström, C.H.; Smith, M.L.; Siesjö, B.K. The influence of mild body and brain hypothermia on ischemic brain damage. J. Cereb. Blood Flow Metab. 1990, 10, 365-374. [CrossRef]

9. Yeon, J.Y.; Seo, D.-W.; Hong, S.-C.; Kim, J.-S. Transcranial motor evoked potential monitoring during the surgical clipping of unruptured intracranial aneurysms. J. Neurol. Sci. 2010, 293, 29-34. [CrossRef]

10. Kim, T.K.; Park, I.S. Comparative Study of Brain Protection Effect between Thiopental and Etomidate Using Bispectral Index during Temporary Arterial Occlusion. J. Korean Neurosurg. Soc. 2011, 50, 497-502. [CrossRef] [PubMed]

11. Kawaguchi, M.; Furuya, H.; Patel, P.M. Neuroprotective effects of anesthetic agents. J. Anesth. 2005, 19, 150-156. [CrossRef]

12. Sano, T.; Patel, P.M.; Drummond, J.C.; Cole, D.J. A Comparison of the Cerebral Protective Effects of Etomidate, Thiopental, and Isoflurane in a Model of Forebrain Ischemia in the Rat. Anesth. Analg. 1993, 76, 990-997. [CrossRef] [PubMed]

13. Kassell, N.F.; Peerless, S.J.; Drake, C.G.; Boarini, D.J.; Adams, H.P. Treatment of Ischemic Deficits from Cerebral Vasospasm with High Dose Barbiturate Therapy. Neurosurgery 1980, 7, 593-597. [CrossRef]

14. Mayer, T.E.; Etminan, N.; Morita, A.; Juvela, S. The unruptured intracranial aneurysm treatment score: A multidisciplinary consensus. Neurology 2016, 86, 792-793. [CrossRef]

15. Morgan, M.K.; Wiedmann, M.; Assaad, N.N.; Heller, G.Z. Complication-Effectiveness analysis for unruptured intracranial aneurysm surgery: A propensity cohort study. Neurosurgery 2016, 78, 648-659. [CrossRef] [PubMed]

16. Burns, J.D.; Huston, J., III; Layton, K.F.; Piepgras, D.G.; Brwon, R.D., Jr. Intracranial aneurysm enlargement on serial magnetic resonance angiography: Frequency and risk factors. Stroke 2009, 40, 406-411. [CrossRef]

17. Michenfelder, J.D. The Interdependency of Cerebral Functional and Metabolic Effects Following Massive Doses of Thiopental in the Dog. Anesthesiology 1974, 41, 231-236. [CrossRef]

18. Drummond, J.C.; Cole, D.J.; Patel, P.M.; Reynolds, L.W. Focal cerebral ischemia during anesthesia with etomidate, isoflurane, or thiopental: A comparison of the extent of cerebral injury. Neurosurgery 1995, 37, 742-748. [CrossRef]

19. Kofke, W.A.; Nemoto, E.M.; Hossmann, K.A.; Taylor, F.; Kessler, P.D.; Stezoski, S.W. Brain blood flow and metabolism after global ischemia and post-insult thiopental therapy in monkeys. Stroke 1979, 10, 554-560. [CrossRef]

20. Musch, T.I.; Pelligrino, D.A.; Dempsey, J.A. Effects of prolonged N2O and barbiturate anaesthesia on brain metabolism and pH in the dog. Respir. Physiol. 1980, 39, 121-131. [CrossRef]

21. Zarchin, N.; Guggenheimer-Furman, E.; Meilin, S.; Ornstein, E.; Mayevsky, A. Thiopental induced cerebral protection during ischemia in gerbils. Brain Res. 1998, 780, 230-236. [CrossRef]

22. Charlesworth, P.; Jacobson, I.; Richards, C.D. Pentobarbitone modulation of NMDA receptors in neurones isolated from the rat olfactory brain. Br. J. Pharmacol. 1995, 116, 3005-3013. [CrossRef]

23. Schmid-Elsaesser, R.; Schröder, M.; Zausinger, S.; Hungerhuber, E.; Baethmann, A.; Reulen, H.J. EEG burst suppression is not necessary for maximum barbiturate protection in transient focal cerebral ischemia in the rat. J. Neurol. Sci. 1999, 162, 14-19. [CrossRef]

24. Almaas, R.; Saugstad, O.D.; Pleasure, D.; Rootwelt, T. Effect of Barbiturates on Hydroxyl Radicals, Lipid Peroxidation, and Hypoxic Cell Death in Human NT2-N Neurons. Anesthesiology 2000, 92, 764-774. [CrossRef]

25. Hindman, B.J.; Bayman, E.O.; Pfisterer, W.K.; Torner, J.C.; Todd, M.M.; Investigators, I. No association between intraoperative hypothermia or supplemental protective drug and neurologic outcomes in patients undergoing temporary clipping during cerebral aneurysm surgery: Findings from the Intraoperative Hypothermia for Aneurysm Surgery Trial. Anesthesiology 2010, 112, 86-101. [CrossRef] 
26. Ramesh, V.J.; Umamaheswara Rao, G.S. Quantification of Burst Suppression and Bispectral Index with 2 Different Bolus Doses of Thiopentone Sodium. J. Neurosurg. Anesthesiol. 2007, 19, 179-182. [CrossRef]

27. Yoon, J.R.; Kim, Y.S.; Kim, T.K. Thiopental-induced Burst Suppression Measured by the Bispectral Index is Extended during Propofol Administration Compared with Sevoflurane. J. Neurosurg. Anesthesiol. 2012, 24, 146-151. [CrossRef]

28. Khanna, R.K.; Malik, G.M.; Qureshi, N. Predicting outcome following surgical treatment of unruptured intracranial aneurysms: A proposed grading system. J. Neurosurg. 1996, 84, 49-54. [CrossRef]

29. Ogilvy, C.S.; Carter, B.S. A Proposed Comprehensive Grading System to Predict Outcome for Surgical Management of Intracranial Aneurysms. Neurosurgery 1998, 42, 959-968. [CrossRef]

30. I Orz, Y.; Hongo, K.; Tanaka, Y.; Nagashima, H.; Osawa, M.; Kyoshima, K.; Kobayashi, S. Risks of surgery for patients with unruptured intracranial aneurysms. Surg. Neurol. 2000, 53, 21-29. [CrossRef]

31. Ji, W.; Liu, A.; Lv, X.; Kang, H.; Sun, L.; Li, Y.; Yang, X.; Jiang, C.; Wu, Z. Risk Score for Neurological Complications after Endovascular Treatment of Unruptured Intracranial Aneurysms. Stroke 2016, 47, 971-978. [CrossRef]

32. Orrù, E.; Roccatagliata, L.; Cester, G.; Causin, F.; Castellan, L. Complications of endovascular treatment of cerebral aneurysms. Eur. J. Radiol. 2013, 82, 1653-1658. [CrossRef]

33. Ashour, R.; Johnson, J.; Ebersole, K.; Aziz-Sultan, M.A. “Successful” coiling of a giant ophthalmic aneurysm resulting in blindness: Case report and critical review. Neurosurg. Rev. 2013, 36, 661-665. [CrossRef]

34. McDermott, M.W.; Durity, F.A.; Borozny, M.; Mountain, M.A. Temporary vessel occlusion and barbiturate protection in cerebral aneurysm surgery. Neurosurgery 1989, 25, 54-61. [CrossRef] [PubMed]

35. Byoun, H.S.; Bang, J.S.; Oh, C.W.; Kwon, O.K.; Hwang, G.; Han, J.H.; Kim, T.; Lee, S.U.; Jo, S.R.; Kim, D.G.; et al. The incidence of and risk factors for ischemic complications after microsurgical clipping of unruptured middle cerebral artery aneurysms and the efficacy of intraoperative monitoring of somatosensory evoked potentials: A retrospective study. Clin. Neurol. Neurosurg. 2016, 151, 128-135. [CrossRef] [PubMed]

36. Elijovich, L.; Higashida, R.T.; Lawton, M.T.; Duckwiler, G.; Giannotta, S.; Johnston, S.C.; Cerebral Aneurysm Rerupture after Treatment, I. Predictors and outcomes of intraprocedural rupture in patients treated for ruptured intracranial aneurysms: The CARAT study. Stroke 2008, 39, 1501-1506. [CrossRef] [PubMed]

37. Tziomalos, K.; Athyros, V.G.; Karagiannis, A.; Mikhailidis, D.P. Dyslipidemia as a risk factor for ischemic stroke. Curr. Top. Med. Chem. 2009, 9, 1291-1297. [CrossRef]

38. Zechariah, A.; ElAli, A.; Hagemann, N.; Jin, F.; Doeppner, T.R.; Helfrich, I.; Mies, G.; Hermann, D.M. Hyperlipidemia Attenuates Vascular Endothelial Growth Factor-Induced Angiogenesis, Impairs Cerebral Blood Flow, and Disturbs Stroke Recovery via Decreased Pericyte Coverage of Brain Endothelial Cells. Arterioscler. Thromb. Vasc. Biol. 2013, 33, 1561-1567. [CrossRef]

39. Kotowski, M.; Naggara, O.; Darsaut, T.E.; Nolet, S.; Gevry, G.; Kouznetsov, E.; Raymond, J. Safety and occlusion rates of surgical treatment of unruptured intracranial aneurysms: A systematic review and meta-analysis of the literature from 1990 to 2011. J. Neurol. Neurosurg. Psychiatry 2013, 84, 42-48. [CrossRef]

40. Jo, K.I.; Kim, H.R.; Yeon, J.Y.; Hong, S.C.; Kim, J.S. Treatment outcomes of surgical clipping for unruptured anterior circulation aneurysm-Single institute experiences in the era of neurophysiologic monitoring and endovascular treatment. Neurosurg. Rev. 2015, 38, 677-682. [CrossRef] 